\title{
Clinical Meaning of Ascites in Patients with Endomyocardial Fibrosis
}

\author{
Antonio Carlos Pereira Barretto, Charles Mady, Sergio Almeida Oliveira, Edmundo Arteaga, \\ Creusa Dal Bó, José Antonio Franchini Ramires
}

São Paulo, SP - Brazil

\begin{abstract}
Objective - To evaluate the clinical meaning of ascites and the main features of patients with ascites and endomyocardial fibrosis.

Methods - We studied 166 patients with endomyocardial fibrosis (mean age 37 years, 114 women) treated over the last 20 years. Ventriculography findings, surgery or necropsy confirmed the diagnosis in all patients. Most patients belonged to New York Heart Association Functional Class III/IV (134, 83.7\%). Eighty-one (50.6\%) had biventricular, 28 (17.5\%) had right ventricular, and 51 (31.8\%) had left ventricular involvement. During follow-up, 56 patients died.
\end{abstract}

Results - Ascites was present in 67 (41.8\%) patients, and right ventricular involvement was present in 59 (88\%). In the comparison between patients with or without ascites, those with ascites had higher mortality (49.2\% and $24.7 \%$, respectively). Patients with ascites had a higher incidence of edema ( $95 \%$ vs. 43\%), hepatomegaly $(5.8 \mathrm{~cm} v \mathrm{~s} .4 .1 \mathrm{~cm})$, mean right atrium pressure (19.3 vs. $12 \mathrm{~mm} \mathrm{Hg}$ ), and final right ventricle diastolic pressure (18.7vs. $12.9 \mathrm{mmHg})$. Also, patients with ascites had a longer history of illness (5.1 and 3.9 years, respectively) and had atrial fibrillation more frequently (44.7\% vs. 30.1\%).

Conclusion - Ascites was observed in less than 50\% of cases of endomyocardial fibrosis and was associated with greater involvement of the right ventricle and with a longer duration of the disease, thus being a characteristic of a worse prognosis.

Keywords: ascites, endomyocardial fibrosis, restrictive cardiomiopathy

Instituto do Coração do Hospital das Clínicas - FMUSP

Mailing address: Antonio Carlos Pereira Barretto - InCor - Av. Dr. Enéas C. Aguiar, 44 - 05403-000 - São Paulo, SP - Brazil - E-mail: pereira.barretto@incor.usp.br Received for publication on $16 / 11 / 00$

Accepted on 14/2/01
Endomyocardial fibrosis is a restrictive cardiopathy that may evolve to cardiac failure, which is difficult to control ${ }^{1-7}$. Its detection enables, in most cases, recommendation for surgical treatment, with resection of fibrotic tissue and control of cardiac failure 2-4,8-10. $^{2}$.

Ascites is a very important feature in the diagnosis of endomyocardial fibrosis. When it is associated with peripheral edema, and even in its absence, it is valued as an indication of a restrictive syndrome and must be taken into account as an etiological factor.

The objective of this study was to evaluate the importance of ascites related to its clinical and laboratory characteristics, for the purpose of evaluating whether the presence or absence of ascites identifies patients with different clinical courses and different prognoses.

\section{Methods}

We studied 166 patients with endomyocardial fibrosis followed at the Instituto do Coração-HC/FMUSP since 1978; 114 were women and 46 were men. Age ranged from 5 to 64 years (mean $34.3 \pm 13$ ). Diagnosis was confirmed by hemodynamic and angiographic studies in 133 patients, by surgery in 88 patients, and by data obtained in necropsy in 30 patients.

Data obtained through angiographic study or necropsy revealed that 81 patients had biventricular, 28 had right ventricular, and 51 had left ventricular involvement. Based on the findings, involvement was classified as mild, moderate, or severe. Involvement of the right ventricle was considered mild in 52 cases, moderate in 52 and severe in 56 cases. Involvement of the left ventricle was mild in 28 , moderate in 82 and severe in 49 cases.

Most patients were symptomatic, and 134 had New York Heart Association (NYHA) functional classes III/IV cardiac failure and 25 had NYHA classes I/II.

During follow-up, 56 (35\%) patients died.

Regarding clinical features, 142 (88.8\%) had dyspnea, 104 (65.4\%) had swelling of the lower limbs, and $112(70.4 \%)$ had 
hepatomegaly. In 96 (65.4\%), regurgitant systolic murmur was present.Proto-diastolicknockwasdescribedin 77(48.4\%) patients. Atrial fibrillation was verified in $58(36.3 \%)$ cases. Ascites was detected by physical examinationin 67 (42.1\%) patients.

During follow-up, 96 patients underwent echocardiographic study. Because follow-up was long, echocardiographies were performed using different machines and techniques; thus, we will only highlight the measures obtained by M-mode, common to all the cases. Mean left ventricle diameter was $51.9 \pm 9.6 \mathrm{~mm}$, left atrium diameter was $42.2 \pm 9.6 \mathrm{~mm}$, and left ventricle ejection fraction was $0.72 \pm 0.09$.

Hemodynamic study was performed in $130(31.2 \%)$ patients. Mean right atrial pressure was $15.0 \pm 7.4 \mathrm{mmHg}$, right ventricular end diastolic pressure was $15.3 \pm 7.1 \mathrm{mmHg}$, left ventricular systolic pressure was $42.9 \pm 20.6 \mathrm{mmHg}$, left ventricular end diastolic pressure was $21.8 \pm 10.4 \mathrm{mmHg}$ and left ventricular systolic pressure was $119.4 \pm 19.7 \mathrm{mmHg}$. Tricuspid regurgitation was observed in $98(61.4 \%)$ patients and mitral regurgitation in $102(63.7 \%)$ patients.

According to ventriculographic appearance, the degree of fibrosis was classified as mild, moderate or severe. Fibrosis was considered mild when small changes were observed in ventricular morphology, mainly a restriction in the inflow tract or apex. Moderate fibrosis was characterized by evident reduction in the diastolic ventricular dimension together with endocardial irregularities of the apical region. Severe fibrosis was characterized by a grossly abnormal appearance of the ventricular chamber in diastole (the chamber being reduced in size and acquiring a tubular form owing to the almost complete elimination of the inflow tract and obliteration of the apex).

Patients were followed annually. Those who failed to attend their scheduled follow-up visit were contacted by telephone or letter or by both telephone and letter at least three times. The mean follow-up period was $4.2 \pm 4$ years. Seventeen patients were lost to follow-up during the first year. Deaths occurred in 56 (34\%) patients, 27 among patients treated clinically and 28 among patients treated surgically.

Patients were divided into 2 groups according to the presence or the absence of ascites. We evaluated whether differences existed between the 2 groups regarding clinical symptoms, or in echocardiographic and hemodynamic findings. Kaplan-Meier survival curves were constructed for those with and without ascites. Differences between the curves were analyzed with the log-rank test. Chi-squared analysis was used to test the association between several variables. A p value $<0.05$ was considered significant. Statistical analysis was performed using SAS (Statistical Analyses Systems) software.

\section{Results}

Ascites was observed during clinical examination in $67(42.1 \%)$ patients treated at our institution. Table I shows clinical characteristics of patients with or without ascites and table II shows echocardiographic, hemodynamic and ventriculographic data. Patients with ascites were younger than those without it.

\begin{tabular}{|c|c|c|c|}
\hline \multicolumn{4}{|c|}{$\begin{array}{l}\text { Table I - Clinical profile of patients according to the presence } \\
\qquad\left(A^{+}\right) \text {or absence (A-) of ascites }\end{array}$} \\
\hline Number & $\begin{array}{l}\text { A+ } \\
67\end{array}$ & $\begin{array}{l}\text { A- } \\
93\end{array}$ & $\mathrm{p}$ \\
\hline Age & $34 \pm 12.8$ & $39.8 \pm 12.6$ & 0.0051 \\
\hline Female & $48(71.6 \%)$ & $66(69.9 \%)$ & 0.892 \\
\hline FC III/IV & $67(100 \%)$ & $68(73.1 \%)$ & 0.001 \\
\hline FA & $37(55.2 \%)$ & $64(69.5 \%)$ & 0.064 \\
\hline Dyspnea & $60(89.5 \%)$ & $81(88 \%)$ & 0.767 \\
\hline Chest pain & $7(10.4 \%)$ & $30(32.6 \%)$ & 0.001 \\
\hline Hepatomegaly & $60(89.5 \%)$ & $52(56.6 \%)$ & 0.001 \\
\hline Peripheral edema & $64(95.6 \%)$ & $40(43.4 \%)$ & 0.001 \\
\hline Proto-diastolic knock & $37(55.2 \%)$ & $40(43.4 \%)$ & 0.143 \\
\hline Systolic murmur & $40(59.7 \%)$ & $56(69.8 \%)$ & 0.882 \\
\hline $\begin{array}{l}\text { Ventricular involvement } \\
(\mathrm{Bi}, \mathrm{RV}, \mathrm{LV})\end{array}$ & $42 / 17 / 8$ & $39 / 11 / 43$ & 0.001 \\
\hline Surgical patients & $42(62.6 \%)$ & $46(49.4 \%)$ & 0.085 \\
\hline Deaths & $34(50.7 \%)$ & $33(35.4 \%)$ & 0.0021 \\
\hline \multicolumn{4}{|c|}{$\begin{array}{l}\text { FC- NYHA functional class; AF- atrial fibrillation; Bi- biventricular } \\
\text { involvement; RV-prevalent involvement of right ventricle; LV- prevalent } \\
\text { involvement of left ventricle. }\end{array}$} \\
\hline
\end{tabular}

\begin{tabular}{|c|c|c|c|}
\hline \multicolumn{4}{|c|}{$\begin{array}{l}\text { Table II - Data from echocardiographic, hemodynamic and } \\
\text { ventriculographic study, according to the presence }\left(\mathrm{A}^{+}\right) \text {or absence } \\
\text { (A-) of ascites }\end{array}$} \\
\hline & $\mathrm{A}+$ & A- & $\mathrm{p}$ \\
\hline Left atrium diameter (mm) & $42.7 \pm 9.2$ & $42.0+8.6$ & 0.7482 \\
\hline Diastolic diameter of LV (mm) & $48.3 \pm 10$ & $53.5 \pm 9.1$ & 0.0131 \\
\hline Ejection fraction of LV (\%) & $71.8 \pm 8.5$ & $72.5 \pm 9.4$ & 0.1342 \\
\hline Pressure of left atrium $(\mathrm{mmHg})$ & $19.2 \pm 6.5$ & $12.0 \pm 6.5$ & $<0.0001$ \\
\hline $\begin{array}{l}\text { Final diastolic pressure } \\
\text { of } \mathrm{RV}(\mathrm{mmHg})\end{array}$ & $18.6 \pm 6.4$ & $12.8 \pm 6.6$ & $<0.0001$ \\
\hline $\begin{array}{l}\text { Systolic pressure } \\
\text { of } \mathrm{RV}(\mathrm{mmHg})\end{array}$ & $38.7 \pm 21.6$ & $46.0 \pm 19.5$ & 0.454 \\
\hline $\begin{array}{l}\text { Diastolic pressure } \\
\text { of } L V(\mathrm{mmHg})\end{array}$ & $20.7 \pm 9.3$ & $22.6 \pm 11.1$ & 0.3091 \\
\hline $\begin{array}{l}\text { Systolic pressure } \\
\text { of } \mathrm{LV}(\mathrm{mmHg})\end{array}$ & $113.1 \pm 16.4$ & $124.1 \pm 20.6$ & 0.0010 \\
\hline Tricuspid regurgitation & $48(88.9 \%)$ & $49(59.7 \%)$ & 0.001 \\
\hline $\begin{array}{l}\text { Mitral regurgitation } \\
\text { Fibrosis intensity }\end{array}$ & $43(76.8 \%)$ & $58(69 \%)$ & 0.317 \\
\hline $\begin{array}{l}\mathrm{RV}(\mathrm{Mi}, \mathrm{Mo}, \mathrm{I}) \\
\text { Fibrosis intensity }\end{array}$ & $9 / 23 / 35$ & $43 / 29 / 21$ & 0.001 \\
\hline $\mathrm{LV}(\mathrm{Mi}, \mathrm{Mo}, \mathrm{I})$ & $18 / 33 / 16$ & $11 / 49 / 33$ & 0.037 \\
\hline
\end{tabular}

On physical examination, patients with ascites frequently had more hepatomegaly and peripheral edema and less chest pain than the patients without ascites. The incidence of dyspnea, proto-diastolic knock, and regurgitant systolic murmurs was the same for both groups.

Patients with ascites had left ventricles with lower diameters on echocardiographic examination $(48.3 \mathrm{~mm}$ vs $53.54 \mathrm{~mm}, \mathrm{p}=0.0131$ ). In the hemodynamic study, patients with ascites had higher mean right atrial pressure and right ventricular end diastolic pressure, and lower left ventricular systolic pressure. In ventriculography, a greater number of patients had tricuspid regurgitation ( $\mathrm{p}=0.001$ ), and the proportion of patients with a greater intensity of right ventricular fibrosis was higher $(\mathrm{p}=0.001)$. 
The proportion of patients who underwent surgery was slightly greater among those with ascites $(62.6 \%$ vs $49.4 \%$ ), but this difference did not reach statistical significance $(\mathrm{p}=0.085)$.

Mortality was higher among patients with ascites $(\mathrm{p}=0.0021)$. Analysis of the Kaplan-Meier survival curves revealed that patients with ascites reached $30 \%$ mortality at two years, while those without ascites had a mortality rate of $15 \%$ at eight years ( $\mathrm{p}=0.00009)$ (fig. 1$)$.

\section{Discussion}

The main findings of this study include: 1 ) ascites is frequent in patients with endomyocardial fibrosis (incidence of $42.1 \%), 2$ ) ascites is usually associated with hepatomegaly and peripheral edema, 3) ascites is related to a greater hemodynamic and morphological involvement of the right ventricle, 4) ascites is associated with the presence of tricuspid regurgitation in the hemodynamic study, 5) presence of ascites is associated with a worse prognosis.

Ascites appears to be a sign frequently found in restrictive cardiomyopathies and is considered an important factor for diagnosis of those entities. It may be present both in constrictive pericardites and in endomyocardial fibrosis, which suggests the need for confirming the diagnosis.

The presence of ascites in patients with endomyocardial fibrosis is mentioned in the majority of articles that discuss the disease ${ }^{1-7}$. It is worth noting that, generally, no special point is made in these articles about stressing its importance; it is presented as another clinical sign of right ventricular involvement. Its incidence ranged between $28 \%$ and $100 \%$ of reported cases. No concern, in most articles, is shown about verifying whether ascites is important in the follow-up of patients. When we compare our analysis with those in the literature, we observe that in the literature the reported frequency of ascites is greater, because in these studies most patients had biventricular involvement or isolated right ventricular involvement. Analyses of patients with prevalent left ventricular involvement, such as ours,

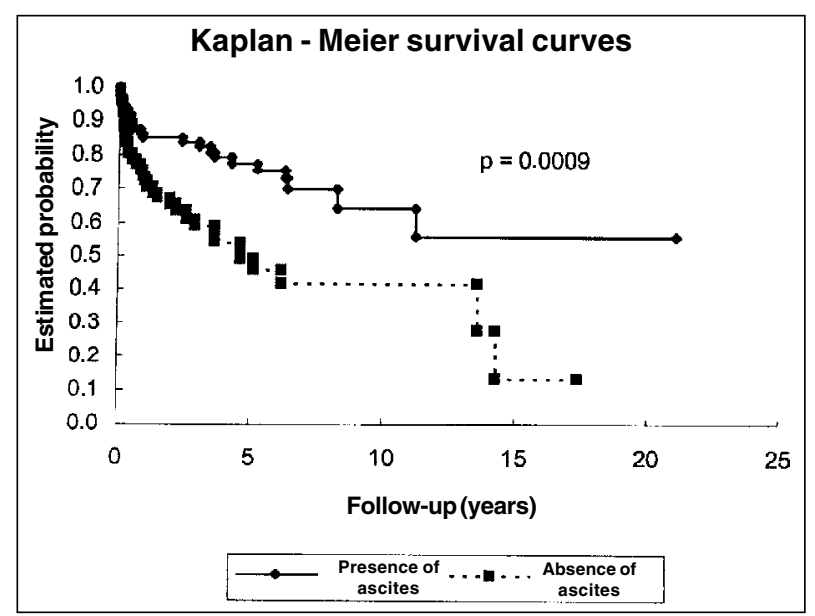

Fig. 1 - Kaplan-Meier survival curves for patients with and without ascites. are rare, because in the majority of the cases, endomyocardial fibrosis is diagnosed because of its congestive manifestations and because of the presence of ascites.

In our data, we have a great number of cases with prevalent involvement of the left ventricle. These patients had chest pain and underwent cineangiography with ventriculography, which facilitates the diagnosis of endomyocardial fibrosis. Ascites was more frequent among patients in whom the disease involved the right ventricle, and the greater the involvement the more frequent the presence of ascites. Thus, in patients with severe fibrosis of the right ventricle, the incidence of ascites was $52 \%$. In those with moderate fibrosis, it was $34 \%$, and in those with mild fibrosis, it was $13 \%$, indicating how important chamber obliteration (fibrosis intensity) is in the restrictive syndrome and in hemodynamic changes that lead to the genesis of ascites.

When we analyzed ascites in relation to the chamber involved, we observed that biventricular involvement was present in $52.5 \%$ of patients, right ventricular involvement was present in $60.7 \%$ and prevalent involvement of the left ventricle was present in $15.6 \%$. These data show the importance of right ventricular involvement.

If right ventricle involvement is the cause of ascites, why do some patients with endomyocardial fibrosis of the left ventricle have ascites? One hypothesis is that at autopsy we can usually detect involvement of both chambers. In many cases, this involvement is not important enough to determine distortions in the chambers and we cannot identify right ventricular involvement in the clinical or laboratory examinations. These cases are identified as dominant involvement of the left ventricle, but, probably, minimal changes in the right ventricle are enough to explain alterations responsible for the appearance of ascites ${ }^{11}$. In fact, this disease is seldom exclusively univentricular. Another possibility is that ascites is due to an inflammatory process of the peritonious. Researchers who have observed the high level of proteins and leptocytosis in ascites effusion defend this hypothesis ${ }^{12}$.

Patients with ascites more often had signs related to the involvement of the right chambers, such as hepatomegaly and peripheral edema, usually present in cases of congestive heart failure. Patients with ascites were younger, what could be related to the characteristics of right heart involvement, because since the right ventricle was a smaller muscular mass, it results in earlier symptoms when compared to the left ventricular involvement.

Atrial fibrillation, which is also associated with a worse prognosis, was slightly more frequent among the patients with ascites, but no statistically significant difference existed between the two ${ }^{13}$. The presence of murmur, identifying mitral and tricuspid regurgitation, was more frequent among patients with ascites. The presence of tricuspid regurgitation increases clinical manifestation in cases of cardiac restriction because the ventricles lose the ability to adapt to the volume of regurgitation, as in cases of endomyocardial fibrosis, which explains the higher incidence of ascites in these patients. 
Data from hemodynamic examinations confirmed this assessment. Patients with ascites had greater elevation in mean pressure of the right atrium and in the final diastolic pressure of the right ventricle, which indicates greater involvement of the right ventricle. They also show that no relation exists between the presence or absence of ascites and the intensity of the involvement and restriction of the left ventricle, because the final diastolic pressures in the left ventricles were similar in both groups.

Mortality was higher in patients with ascites, which may be because it is a clinical manifestation of right ventricular involvement, which is associated with a worse prognosis, as is reported in the literature ${ }^{1-7}$. Right ventricular involvement characterizes a group with greater cardiac obliteration and a higher frequency of tricuspid regurgitation, both of which are clinical situations that aggravate the evolvement of patients with this disease.
We verified that ascites was slightly more frequent in patients referred for surgery, a finding that was probably related to the greater difficulty in clinically controlling these patients, a condition in which surgery is recommended.

Kaplan-Meier survival curves (fig. 1) show that the prognosis of patients with ascites is poorer than the prognosis of those without ascites. These curves differ from the beginning of the study and separate progressively.

The results of this analysis confirm that right ventricular involvement is more harmful to patients and, in those with clinical manifestations such as ascites, surgery must be recommended as early as possible, because it can reverse or minimize hemodynamic alterations that determine this worse evolvement, improving the patient's prognosis, according to several studies ${ }^{2-4,8-10,13}$.

\section{References}

1. Somers K, Brenton PP, Sood NK. Clinical features of endomyocardial fibrosis of the right ventricle. Br Heart J 1968; 30: 309-21

2. Bertrand E, Chauvet J, Assamoi MO, et al. Results, indications and contra-indications of surgery in restrictive endomyocardial fibrosis: comparative study on 31 operated and 30 non-operated patients. E Afr Med J 1985; 62: 151-60.

3. Metras D, Coulibaly AO, Ouattara K. The surgical treatment of endomyocardial fibrosis: results in 55 patients. Circulation 1985;72: II-274-9.

4. Valiathan MS, Balakrishnan KG, Sankarkumar R, Kartha CC. Surgical treatment of endomyocardial fibrosis. Ann Thorac Surg 1987; 43: 68-73.

5. Fujita PN, Valiathan MS, Balakrishnan KG, Kartha C, Ghosh MK. Clinical course of endomyocardial fibrosis. Br Heart J 1989; 62: 450-4.

6. Dubost C, Chapelon C, Deloche A, et al. Chirurgie des fibroses endomyocardiques. A propos de 22 cases. Arch Mal Coeur 1990; 83: 481-6.

7. Pereira Barretto AC, Luz PL, Oliveira SA, et al. Determinants of survival in endomyocardial fibrosis. Circulation 1989; 80: I-177-82.
8. Oliveira SA, Pereira Barretto AC, Mady C, et al. Surgical treatment of endomyocardial fibrosis: A new approach. J Am Coll Cardiol 1990; 16: 1246-51.

9. Cherian G, Vijayaraghavam G, Krishnaswami S, et al. Endomyocardial fibrosis Report on the hemodynamic data in 29 patients and review of the results of surgery. Am Heart J 1983; 105: 659-66.

10. Moraes CR, Buffolo E, Lima R, et al. Surgical treatment of endomyocardial fibrosis J Thoracic Cardiovasc Surg 1983; 85: 738-45.

11. Lopes EA, Pereira-Barretto AC. Endomiocardiofibrose: estudo morfológico baseado em 25 casos necropsiados no InCor. Arq Bras Cardiol 1988; $51: 94$.

12. Freers J, Mayanja-Kizza H, Rutakingirwa M, Gerwing E. Endomyocardial fibrosis: why is there striking ascites with little or no peripheral oedema? Lancet 1996; 347: 197

13. Pereira-Barretto AC, Mady C, Nussbacher A, et al. Atrial fibrillation in endomyocardial fibrosis is a marker of worse prognosis. Int J Cardiol 1998; 67: $19-25$. 